\title{
The Philosophical Reset Button: A Manifesto
}

\author{
Michael Slote
}

Published online: 29 January 2015

(C) Springer Science+Business Media Dordrecht 2015

\begin{abstract}
This article is very different from other philosophy articles: it really is a manifesto addressed to Chinese philosophers. On the whole, Western thought has been exceedingly intellectualistic and rationalistic, and in this article I outline some of the ways in which those deep one-sided tendencies need to be corrected or rebalanced. However, I also claim that the Chinese are in the best position to correct and rebalance philosophy as a discipline. Chinese thought has never gone to the extremes of Western rationalism, and there is every reason to think that as China gains in power and prestige throughout the world, Chinese philosophers and thinkers will be in a position to correct or reset Western philosophy by drawing on their own deepest historical traditions, traditions which have recognized the value of emotion and sane ordinary living much more than has been typical in the West. You Chinese should realize that you have much to offer the West and not be too modest with your self-image or reticent with your philosophical ambitions.
\end{abstract}

Keywords Chinese philosophers $\cdot$ Western rationalism $\cdot$ Emotion $\cdot$ Empathy $\cdot$ Reset button

It's time to press the reset button for our philosophy. I am talking here about Western philosophy-I will bring non-Western philosophy into the picture a little further along. What I think we see in the history of Western philosophy since Plato is rationalism run amok. The Greeks were the first Western philosophers, and they had an extreme and extraordinary resistance to sheer bodily existence that is difficult, actually, to understand. No one told them, as certain strands of Christianity tell their adherents, that the body is dirty or dangerous. They seemed to have picked up that idea on their own and for themselves, and I am not sure anyone has ever tried to explain how this happened or why. But happen it did. Plato tells us (S. 499-500) that we should try to remove ourselves as much as possible from our bodily existence (and should emulate the Forms). Aristotle tells us a life of pure theorizing is the highest kind of existence.

Michael Slote $(\varpi)$

Department of Philosophy, University of Miami, Coral Gables, FL 33124, USA

e-mail: mslote@miami.edu 
Kant tells us we should or would wish if possible to be free of bodily inclinations. And so it goes.

But what, you may ask, does this have to do with excessive rationalism? Well, the rejection of the body goes hand in hand with a rejection of emotions, which seem bodily in a way our cogitations do not. I am not sure whether the fear of emotion fuels the distaste for the bodily or vice versa. This is something the historians might want to study or study further-I am not aware, at any rate, of their having said anything useful or edifying on this particular question. (I guess such historians would be doing a kind of psycho-history directed at the history of philosophy — but such a thing might well repay pursuing.) And, of course, the idea that in the patriarchal mentality of traditional Western thought emotion, body, and the feminine are contrasted with reason, mind, and the masculine is well-known to all of us. But nowadays we are not so swift to tie the feminine with what we think less well of. Sensitive males are supposed to accept and thrive on their emotions - not to avoid them as much as possible. Can philosophy learn a lesson from all this?

Others have spoken in roughly the way I have just now been speaking. They have deplored what has gone on in the West, but the real test of such objections is whether they propose an attractive alternative. I don't think anyone has. One reaction to the sort of thing I have been saying is to move toward an irrationalism that glorifies the emotions at the total expense of reason (Nietzsche moves in this direction). Another possible reaction is to give up on philosophy as philosophy, as a search for wisdom and truth, and this is what we find often or usually in Continental post-modernism.

However, what if we could keep hold of philosophy as philosophy and still overcome the overwhelming bias, in the West, in favor of rationality? What if we could in a reasoned and sober manner that was more open to what the emotions have to teach us proceed with or toward a more balanced philosophy that treats reason and emotion as more equal partners in what is valuable in human thought and human life? But we need an incentive, an argument, for doing this. Thomas Kuhn has taught us that we are reluctant, and more than reluctant, to give up a theory in the absence of a new and better theory to grab onto. The same holds, certainly and a fortiori, of a tradition, of a general approach to a certain area of thought or speculation. A reset button is only relevant if we have some idea of what we are resetting to and some philosophical or personal motive for wanting to see such a reset. Who among us actually has such a motive?

When I look at the current scene in Anglo-American or Anglophone philosophy, I see philosophers who are quite content to keep going on as they have in the past: placing emotion and its accompaniments like empathy to one side or at the edge of things in favor of what I can only call a purely rational or cognitivist approach to the issues being dealt with. I have no objection whatsoever with dealing with those issues. But I think we need to take off the blinkers when we do that, and I don't see much hope coming from the direction of recent work in Anglophone philosophy. To be sure, the women's movement has given rise to work - for example, feminist standpoint epistemology and care ethics - that takes a wider or deeper view of what is relevant to philosophical issues than is prevalent among most present-day analytic philosophers. However, the analytic philosophers pretty much ignore these developments, and that fact, I must say, puts me in mind of what Carol Gilligan's great book In a Different Voice: Psychological Theory and Women's Development says about men in relation to 
women. Gilligan characterized traditional or patriarchal/sexist societies as societies where women's and girls' voices aren't paid real attention, aren't really listened to. ("Surely, you don't really want to be a doctor, dear, when it is so much more appropriate for you to be a nurse or homemaker, instead.") And I dare say the same thing has been happening in the philosophical academy over recent decades as intellectual pioneers like Gilligan have made the case for a different or broader view of what is relevant to philosophy (not just to ethics, but to our understanding of our identities and our minds more generally).

The ethicists (in the broadest sense) just haven't paid attention. For example, Derek Parfit's monumental two-volume work On What Matters treats ethical issues as arising fundamentally from the need for a system of rules that we can publicly live by-but he never considers Gilligan's much-earlier-stated view that the way males are typically raised, brought up, gears them toward a public-rule-based view of morality in a way that doesn't so standardly happen with women. I don't know about you, but if I were Parfit and were listening (listening!) to what Gilligan has said in her famous book, I'd be a bit worried. I would think to myself: well, aren't I assuming just the kind of view that a typical male upbringing gears one toward? And that would make me worry in a way that Parfit shows absolutely no sign of worrying. He wasn't listening to Gilligan's academic but female voice. The same is true of the contractualists who follow Rawls in treating moral/political issues as issues about the rules we ought to agree to: philosophers like T. M. Scanlon, Stephen Darwall, and, of course, Rawls himself. There is no sign that any of them has paid serious attention to the issues raised by Gilligan in her book - and everything seems to go on much as it did before Gilligan wrote. What blinkers! What a pity!

Nor is the narrowness I am talking about confined to ethics-far from it. As the notion and phenomenon of empathy has come more and more to the fore in recent academic and public thinking, the idea that emotion may be more central to cognition than has historically (in the West) been thought might have been taken more seriously than in fact it has been. However, if you look at the work of recent analytic epistemologists and philosophers of mind, everything seems to be going on as it did before, and no one pays any attention to other possibilities. You may ask, why should they? Doesn't one have to argue, not just assert, that their approach misses out on important things (one doesn't have to argue that they don't make interesting discoveries in their own somewhat narrow vein)? Yes, one does. And this paper is the result of my own arguments precisely in that direction. My recent work has tried to point to particular possibilities that the tradition has ignored, I have sought to give arguments, and I am not the only one doing this. So, yes, one needs to give an argument for claiming that the Western thinkers have ignored important possibilities and realities. But since Western thinkers don't think their thinking is involved in any sort of crisis, then (as Kuhn again tells us) they aren't likely to listen seriously to those who attack their main rationalist/ cognitivist paradigm. So is there any possibility that things could change?

Yes, there is, and the main possibility for change comes from China: possibly also from India and Japan, but especially China. Chinese thought has never bought into the kind of rationalism that comes so easily and strongly in the West, and as China and other non-Western countries gain in intellectual influence over the next decades, that influence may in effect help to successfully push the reset button in a way that doesn't seem possible, on its own, from inside the Western tradition. 
Let me put some flesh on these bones of contention. Let me sketch for you some of my main reasons for thinking that we need to push the reset button for (Western) philosophy and let me also explain why I think the philosophers of China (possibly aided and abetted by women thinkers here in the West - a virtuous, helpful fifth column) may be able to successfully push it. And I want to sketch for you reasons for thinking that the need for resetting arises out of more than one area of philosophical thinking. In epistemology, in the philosophy of mind, and in ethics, there are large-scale limitations and imbalances - involving false assumptions - in current-day thinking that need to be corrected.

For example, epistemologists in the West, analytic philosophers doing epistemology, have yet to reckon with the significance for their field of empathy and emotion. To be sure, it is generally recognized that emotion can sometimes help us better know the world (one's fear can be a reliable sign that there is danger in the offing) and that empathy can put us cognitively in touch with other people more directly or more successfully than other modes of epistemic access (if I empathically register your pain, that can be a faster way of recognizing its existence and character than any form of rational inference could make available in a given set of circumstances). However, empathy and emotion can and do play a much larger role.

It has not been recognized, for example, that empathy can put us directly in touch not only with the attitudes or beliefs of others, but also with what they know about the world outside of themselves. To take just two obvious examples, the child who empathically imbibes his parents' fear of snakes or their trusting attitude toward Aunt Tilly can thereby be put in cognitive touch with the dangerousness of snakes or the reliability of Aunt Tilly. That is, they learn something important beyond what their empathy with their parents teaches them about their parents. And (again being brief because I discuss these issues at great length elsewhere) empathy also has an important role in the transmission of knowledge via speech acts of assertion (also of asking questions). Speech acts theorists have focused on the intentions of assertors, the fact that they intend their audience to recognize their intention for the audience to believe what they believe about the subject matter of their assertion and to be led to have such belief on the basis of their recognition of that original speaker intention. Although there have been counterexamples to analyses of speech acts along the just-mentioned lines, the real problem with such accounts of how speech acts work is that they ignore the role of empathy in the success of normal speech acts. Hume pointed out in the Treatise that people's opinions and attitudes tend to empathically (though Hume used the word "sympathetically" - since the word "empathy" hadn't yet been invented) seep into those around them. In his early article "The Emotive Theory of Moral Judgments" (Mind, 1937), Charles Stevenson says that moral judgments have a magnetism or dynamism that allows the feeling expressed by the assertor of a moral judgment/ utterance to spread by contagion to those around him/her. But Stevenson could have made his rather Humean point more generally. He could have said-as I now wish to say - that the confidence and conviction felt by the maker of a sincere assertion tend to convey themselves empathically - contagiously - to those who hear the assertion being made (or even, though less strongly, to those who read an author's assertion). Normal speech acts of assertion work as effectively as they do at least in part because of this 
normal human empathic transmission of opinion and attitude, and this is something those who have written about speech acts like assertion (and the role of empathy in the asking of questions and the giving of commands could also be usefully described) have, to the best of my knowledge, totally ignored. It has mainly been implied or assumed, rather, that the recognition of the intention of an assertor to get herself believed becomes the basis for some kind of hearer argument/inference to the conclusion that what the assertor says is likely to be true. This overintellectualizes what is in great part a receptively empathic process.

Let me now give you a second, major example where empathy and, in this case, also emotion have a clear but previously unrecognized role to play in the gathering of knowledge and the epistemic justification of beliefs. Virtue epistemologists have in recent years placed a certain amount of emphasis on the virtue of open-mindedness, more than epistemologists outside that new tradition have tended to do. However, no epistemologist has pointed out the role, the essential and grounding role, that empathy and emotion both play within the epistemic/rational virtue of open-mindedness.

There are known to be two types of empathy: the projective kind, which involves being able to get inside the heads of others; and the associative or receptive kind, which involves actually identifying with the other person, actually seeing things, however briefly, from their point of view. The con artist who knows how to get into other people's heads and who is good at reading what they are thinking or feeling doesn't actually identify with the other person and their feelings/beliefs. They remain, throughout, at a certain cool distance. But if someone is good at getting into people's heads and does so only in order to be able better to refute their ideas and arguments, they are not being open-minded - they are more like the psychopath or con artist who is just very good at mining others for useful information. Rather, open-mindedness requires us to identify, however briefly, with another person and their feelings/beliefs. It involves seeing things, however briefly, from the other person's point of view, and this clearly means that it involves the receptive kind of empathy. It also means that it involves emotion. For if I see things from the point of view of the other, I to that extent sympathize with their point of view, and sympathy is an emotion: in this case directed toward a point of view or set of ideas, rather than a person, but just as truly an emotion as any other literal form of sympathy is. (Can one have sympathy for the goals of some political party without having some sort of emotional response to the goals or ideas of that party?) Empathy and emotion have an essential role to play in an important intellectual/epistemic virtue and thus in epistemic rationality as a whole, but this simply hasn't been recognized by anyone doing epistemology.

This epistemological role entails a similarly important role for emotion (though not so much perhaps for empathy) within the philosophy of mind. In discussing openmindedness a moment ago, I suggested that the rationally open-minded person has some measure of sympathy for (non-crackpot) views they initially at least disagree with, and this sympathy is achieved if one is genuinely open and receptive, empathically, to what others believe. However, this sympathy and empathy make all the more sense if there is an emotional or attitudinal component or aspect to people's views and arguments because it is easiest to imagine empathy occurring toward something colored by some degree of emotion. I believe that opinions are in fact generally colored by such affect or emotion. 
To believe in some hypothesis or view of things one has to favor it over other incompatible hypotheses or views, and there is absolutely no reason to think that this talk of favoring is purely metaphorical or figurative. When we favor one political party or nephew over another, there is an affective component or aspect to our attitude of favoring, and although the favoring of an idea or argument has something more abstract, perhaps, as its object or target, it is still an act or attitude of favoring and that means it involves affect or emotion. In recent and not-so-recent analytic philosophy beliefs have been seen as inert or as having a strictly mind-to-world direction of fit, but if what I am saying now is correct, they aren't as lifeless or "purely cognitive" as we have thought. To believe is, in effect, to have a cognitive attitude, and attitudes are neither inert nor lifeless.

One bit of evidence for this concerns the way we react when someone comes out and blankly questions something we firmly and confidently believe in. Our typical reaction will be to say something like "Oh, come on now!"; and we are likely to be upset and annoyed when what we take to be obvious or thoroughly established is called abruptly into question. (How would someone who knew perfectly well that the Empire State Building is in New York City react if a person told them out of the blue that the Empire State Building is in Albany, the capital of the "Empire State" New York?) We are thus emotionally invested in our beliefs in a way that is incompatible with their total inertness, and there is further evidence for this in the way we tend to defend (and say we are defending) a belief that we think has been (intellectually) unfairly attacked. However, with the exception of certain German Romantics like Max Scheler and Friedrich Schleiermacher, no one in the West has pointed to such a connection or interpenetration of the cognitive and the affective as belief in fact, arguably, exemplifies. Even the Pragmatists, who emphasized the active or habitual element in beliefs, didn't home in on the affective side of belief, so the overall picture we get from the history of Western philosophy is of a philosophical culture or discipline that is blinkered with respect to the role, the central role, emotion plays in the human mind. After all, belief is central to the mind's major functions (as well as to intentional action) so quite a lot has been misconceived or ignored within the Western traditions of philosophy of mind. Those traditions discuss emotion, to be sure, but they keep it to one side, treat it as precisely not essential to the mind's most essential functions, and that, as I have indicated, shows, again, the one-sidedness or blinkeredness of our Western tradition in this important area of philosophy.

Finally, let me say something fairly briefly about the neglect of empathy and emotion by our Western traditions of normative ethics and political philosophy. And let me begin with the notion of respect. This notion has very little applicability to or within the philosophies of Plato or Aristotle, but the Stoic Seneca's idea that human beings have a dignity that is beyond price (not to mention the Stoic idea that all human beings have the divine spark in them) does gesture strongly in the direction of modern moral notions of respect. In the modern and especially our contemporary world the idea of respect goes hand in hand with that of moral rights. However, neither the Stoics nor the modern/contemporary philosophers who argue for basic human rights and a moral imperative of respecting such rights allow emotion and empathy to play any positive role in their thinking. Those who insist on the honoring of or respect for human rights characteristically justify what they say in terms of our capacity rationally to understand or intuit what is owed to human beings as such, and we see a prime example of such 
thinking in the idea, articulated in the American "Declaration of Independence," that certain moral-political truths are self-evident, among them that human beings have a right to certain basic civil and political liberties.

For example, then, according to the Western mainstream tradition, people have a right to worship freely, and we all can see, rationally or intuitively see, that we have to respect that right even when the religious beliefs and practices we thus tolerate and allow are distasteful to us, even when we dislike them or look down on them. This rationalist way of understanding respect for other people has deep problems, however. To really respect other human beings in the fullest sense, it is not enough to tolerate their religious practices with continuing distaste and disgust - we have to make an effort to understand the point of view of those whose religious practices differ so totally from our own. If we don't reach out to them in this way and simply allow ourselves to continue condemning them, then we haven't been fully respectful toward them. Just as the parent who doesn't listen to their child's protests at being asked/forced to practice the violin six hours a day in order to become the great concert violinist their parent wants them to become - just as that parent isn't being respectful to their own child, so too is it less than fully respectful to allow oneself to keep hating other people's practices or thinking without making an effort to see things from their very different standpoint. So empathy, receptive empathy, has an important and even a crucial role to play in the central modern moral-political ideal of respect, but our Western tradition has totally ignored or neglected this aspect of respect and has favored a totally rationalistic version/understanding of that ideal.

Let me offer you another example of how empathy and in this case also emotion are central to morality in a way that our Western tradition has totally ignored. Almost our entire modern moral tradition grants the importance of altruism to morality and to being moral. However, believe it or not, that tradition doesn't recognize any place for empathy and empathic identification with the emotions of others in the human capacity for altruism and in our moral obligations to care intrinsically about other people. Kant, for example, thinks altruistic motivations like compassion, benevolence, and sympathy for others really aren't altruistic, but his arguments to that effect are deeply flawed (in a way that was or would have been obvious to Joseph Butler), and most contemporary ethicists aren't willing to say that compassion and the like are basically egoistic motives. But even those who recognize that fact don't recognize the central place that empathy (with the emotions of others) has in ordinary, familiar human altruism.

Now the care ethicists are a notable exception. They see the role of empathy, they talk about the role of empathy (sometimes or often), but almost none of this has rubbed off on "mainstream" rationalist thinkers, for whom, in some funny way, altruism in the form of compassion or sympathy is just some sort of basic fact about human motivation. In fact, however, altruism in its most ordinary instances is rooted in empathy, and let me now briefly explain why I say this.

I mentioned above Hume's view that people's attitudes and opinions tend to seep into, "infuse themselves" into, those who are around them. (Hume also speaks of how feelings spread by "contagion" into other people.) But think what this means. When I take in my parents' high opinion of Winston Churchill via empathic osmosis (and that is how it happened with me and happens with others), I don't just take in some kind of generalized, unfocused good feeling, I take in good feeling about or directed toward Churchill. Similarly, when a father is infected by his daughter's enthusiasm for stamp 
collecting, he doesn't just take in enthusiasm or positive feeling, but takes such things in as (intentionally) directed at stamp collecting. By the same token, when someone is in pain and distressed at being so, an empathic observer doesn't just take in negative feeling on the part of the person in pain. They empathically take in the other person's distress at the pain they are feeling. (Writers on the subject of mirror neurons tell us that when we feel another's pain, we or our brains mainly mirror or feel the same kind of distress the other feels and don't necessarily mirror or feel all the phenomenology of the other's pain sensations.) Now the distress the other person feels at or about their pain constitutes in itself (some) motivation on their part to get rid of that pain - that much is built into our notion of distress. But, then, if we empathize with that distress, we too will be motivated to try to lessen or end that distress, their distress, and such motivation is by its very nature altruistic.

This seems to me to be the or a basic mechanism of or for altruistic motivation in human beings - and though other motives may often interfere with or preempt such motivation, there are, I believe, many, many typical human cases where such altruistic motivation eventuates in altruistic actions (without there necessarily being any ulterior or egoistic motives pushing one to act altruistically). But none of this is recognized in mainstream moral and political philosophy, and this is just one further reason why I think we need a philosophical reset. So I am not just claiming in this manifesto that philosophy needs a reset-I am giving reasons for that conclusion, reasons based on showing, though I have only here sketched the arguments, that the basic philosophical assumptions and approaches of our Western tradition are fundamentally flawed.

However, as I said earlier, the Western analytic tradition isn't likely to be very much swayed, much less derailed, by these sorts of arguments. The feminists, for all their efforts, haven't made much of a dent in the philosophical armor of Western philosophizing, and so a successful reset may have to come from outside, and I think the Chinese are the "outsiders" who are most likely to be able to push the necessary reset button in a successful way. Let's face it. The present power and influence of American philosophy developed out of the relative success of the United States in the Second World War. After the war, Germany and Austria were in ruins and their philosophers were drawn toward the United States where there was both money and opportunity enough to give them a philosophical home. Something similar, though less drastic, eventually occurred with British philosophers and British philosophy, which, despite the strong lingering influence of Wittgenstein, has become increasingly involved with American ways of seeing and pursuing the enterprise of philosophy.

However, nowadays the Chinese and their influence are being increasingly felt both politically and philosophically in the larger world, and the Chinese, especially the Confucian, tradition of philosophical thought contains ideas and perspectives that are arguably well-geared toward the kind of philosophical reset I have been arguing for. I have been saying, not that reason is unimportant, but that empathy and emotion deserve a central role too in our attempts to deal with issues in philosophy of mind, epistemology, ethics, and other areas of philosophy. (I have argued elsewhere, in my forthcoming Sentimentalist Virtue Epistemology, that emotion has an unsuspected but central role to play even in what the philosophy of science needs to say about scientific method.) So let me now explain briefly why I see Confucianism as a welcoming home to the sorts of ideas I have been defending here and as a possible or probable source, therefore, of a resetting of philosophy. 
Let's start with the philosophy of mind. The Confucians and, arguably, Chinese thinkers more generally don't conceptually separate cognition and emotion in the way that comes so naturally (but is it natural?) to Western thinkers, who, for example, regard most ordinary beliefs as inert and purely intellectual or purely cognitive. Perhaps the strongest proof of this comes from the Chinese language itself. The Chinese word xin 心 is typically translated "heart-mind," and in keeping with this, Chinese philosophers, unlike their Western counterparts, have a certain tendency not to think of cognition/reason and emotion/empathy as separate faculties or operations of the mind. (The Japanese term kokoro 心 is also standardly translated as "heart-mind," but, it is interesting to note, there is no Indo-European language containing such a term.)

Now Western philosophers who see this Chinese tendency are likely to attribute it to a failure to recognize or understand an important distinction that Western thinkers have succeeded in making. But in the light of what I said earlier, the shoe may actually be on the other foot. If belief involves affect after the manner of our earlier discussion, then it is the Western philosophers who insist on separating, conceptually separating, reason/ cognition/belief on the one hand and emotion or affect on the other who are making the conceptual mistake here. If contemporary Chinese philosophers are willing to draw, confidently, on their own tradition, then they are, I think, in position to insist that they aren't making the kind of conceptual mistake Western philosophers might assume, aren't naively running together what careful philosophical analysis can show are really separate aspects or parts of the mind. They might or can therefore insist on or argue for a reset of our thinking, our Western thinking, about the nature of the mind and its functioning. Of course, as I suggested earlier, the increasing influence of China may make it in the future possible and even inevitable that Chinese thinkers will argue for or insist on this sort of reset in the philosophy of mind.

It will be all the more possible for them to do so, if the Chinese traditions in areas like ethics also tend in this same general direction-toward a lesser or not so total emphasis on the role and value of reason. And in ethics the possibility for the Chinese to argue and push in this direction comes, I think, from the significance and attractive power of the age-old Chinese distinction/complementarity of yin 陰 and yang 陽. (There is also the fact that, in line with their not distinguishing sharply between cognition and emotion in their philosophizing about the human mind, the Confucian tradition contains no examples of a purely rationalist approach to ethics of the sort one finds in Kant or, for that matter, Aristotle. But I think I have said enough in this direction.) In an article called "Updating Yin and Yang" published in the journal Dao in 2013, I argued that that distinction needs updating, but that, updated, it offers a more balanced picture of the ethical life than what basically comes out of our Western tradition. The Western ethical tradition is mainly rationalistic, but even the sentimentalist exceptions, such as Hume, don't emphasize the need for balance as between yin and yang, a distinction which, as I argued in my article, can for present-day ethical and philosophical purposes be equated with the distinction between receptivity and rational control. The Western near-total emphasis on rational control at the expense of receptivity can be seen in numerous instances during the history of philosophy in the West. I have discussed many of those instances in the article mentioned above (and describe further examples and discuss these matters at much greater length in my 2013 OUP book From 
Enlightenment to Receptivity). Let me give you a couple of examples to illustrate what I mean in saying that the West has overemphasized rational control or yang at the expense of receptivity or $y$ in.

Aristotle, in the Eudemian Ethics, and, following him, John Rawls, in A Theory of Justice, have claimed that the only sensible or rational way to lead one's life is by having an overall plan of life which, however conditionally stated and how subject it may be to eventual revision, takes in all of the good things one may want to have in one's life. However, aside from the fact that life can teach one about what things are good in a way or to an extent that this couldn't be anticipated in a life plan formulated in advance, there is also the perhaps more worrisome fact that many of those things we all recognize as good (for us or in our lives) are precisely things one cannot or cannot sensibly plan for. Here I have in mind love and friendship most particularly —it doesn't make sense to plan to fall or be in love, and even the idea of planning to get married seems to overestimate the control we have over such things. We have to be receptive to love; however, although we can register with a dating site or undergo psychotherapy to help us get rid of some of our hang-ups vis-à-vis love, we can't take rational control/ charge of the attainment of these goods in the way a life plan that is supposed to cater to all of life's basic goods might lead us to expect that we can.

But then consider too the typical liberal emphasis on rationally and critically scrutinizing everything in one's life - every feeling, belief, and relationship — before one accepts it into one's life or allows oneself to let it continue to exist in one's life. Again, this seeks to put our lives under our rational control, but does it really make sense, is it even healthy? To be sure, women, most women, should pay more attention to the character of their relationships with male significant others, should ask themselves more whether what they have with a given male is really good or even healthy for them to have. But that fact comes out of empirical, though very general, facts about the way men treat and have treated women. It doesn't tell us that in general and a priori and independently of such facts we should be suspicious and critical about our feelings, relationships, and so on, so that, for example, it is a rational mistake to keep on loving one's children or one's parent without (first) considering in a serious critical way whether such relationships are good or good for one. Surely such suspicion is overdrawn, hyperbolic, and someone who really would be inclined to subject everything in this way to critical scrutiny could well be charged with an unhealthy and practically irrational lack of receptivity to, and even gratitude for, what life has brought their way.

Now receptivity isn't the same thing as and doesn't entail empathy or emotion - not at least in these kinds of cases. (Empathy and emotional identification with the distress of another, however, clearly does involve receptivity to the reality or feelings of the other.) One doesn't have to count as empathic, I think, just because one doesn't have a general a priori tendency to subject everything in one's life to rational scrutiny. But the person who does subject everything to such scrutiny does count as (unfortunately) lacking in receptivity. Our earlier example of life-planning illustrates the same point. Perhaps the person with an overall plan of life doesn't count as lacking in empathy or emotion, but they certainly count as lacking in what I would like to call the virtue of receptivity. Our Western tradition doesn't in these instances and many, many others recognize the value or virtue of receptivity, and the Chinese distinction between and complementarity of yin and yang does, I think, allow for a more balanced ethical approach that assigns great value to both receptivity and rational control. So once again 
the limitations, the misperceptions, of our Western tradition could be and can be corrected, reconfigured, or reset if we rethink our ideas and values in the light of ideas that come naturally to Chinese philosophy and that the Chinese may eventually be in a position to push hard with us Westerners.

\section{4}

Chinese thought has fundamental lessons to teach the West. What I have said earlier in this manifesto is strong evidence for that conclusion - as is the fact, perhaps, that it is a Western philosopher who has only in recent years learned about Chinese thought who is acknowledging that need. But let us also, and finally, spread our net a bit more widely. In addition to the major philosophical issues I spoke of above, there are some more basic differences between Western philosophy and Chinese philosophy that, again and overall, tend to favor the Chinese. In ancient Western thought there was a tendency to devalue the human body and its appetites that never-fortunately-found any parallel within mainstream Confucian thought. China has known how to appreciate ordinary human life (when it isn't burdened by war, oppression, disease, and hunger) in a way the West has taken much longer to do. And, as I have indicated again and again, the West devalues emotion in an unhealthy or at least blinkered way that China never has. So, you Chinese, don't be diffident about what you can contribute or give to the West! Even though your traditions have unfortunately not paid the kind of attention to human rights that one finds in later Western ethical thought, your philosophical ways have on the whole been much more balanced, much fairer to ordinary real living, than the West has been. You will be in a position to teach the West that lesson, those lessons, because in the future the overall power of China is going to be felt much more strongly than it ever has been-worldwide. So have the full courage of your own historic philosophical convictions! Help us (the world, the West) push that reset button! I can see no reason why you shouldn't be able to accomplish that. 